\title{
Current treatment methods for long occlusions of the femoropopliteal segment in patients with intermittent claudication: Minireview
}

\author{
Jana Fialova ${ }^{a}$, Petr Utikal ${ }^{\mathrm{a}}$, Petr Bachledaa ${ }^{\mathrm{a}}$, Martin Kocher ${ }^{\mathrm{b}}$, Marie Cerna ${ }^{\mathrm{b}}$, Katherine Vomackovac
}

\begin{abstract}
Backround. Intermittent claudication is a classic symptom of peripheral arterial disease. It is mainly treated conservatively but if this fails, a form of revascularization is indicated. The revascularization in chronic occlusion of femoropopliteal region is currently performed by two basic methods: the standard method of surgical bypass and the newer miniinvasive alternative represented by the endovascular method. The treatment of patients with solely claudication and long occlusion of femoropopliteal region remains controversial. The aim of this minireview was to determine whether surgical bypass is still the best method of choice in a time of endovascular techniques.

Methods. A MEDLINE search for original and review articles using key terms, intermittent claudication and long femoropopliteal oclusion.

Results and Conclusion. No ideal treatment for long occlusions of the femoropopliteal segment has been established to date. It is clear that the role of endovascular techniques in the treatment of SFA occlusions is increasing. It remains that, lower risk patients with claudication should be examined to assess the quality of veins suitable for revascularization and bypass should be selected as the first method of choice.
\end{abstract}

Key words: occlusion of femoropopliteal region, intermittent claudication, femoropopliteal bypass, percutaneous transluminal angioplasty, subintimal angioplasty

Received: August 23, 2012; Accepted: February 28, 2013; Available online: March 25, 2013

http://dx.doi.org/10.5507/bp.2013.018

${ }^{a}$ Department of Surgery II - Vascular and Transplantation Surgery, University Hospital Olomouc, Czech Republic

${ }^{b}$ Department of Radiology, University Hospital Olomouc

'Department of Surgery l, University Hospital Olomouc

Corresponding author: Jana Fialova, e-mail:jana.fialova@email.cz

\section{INTRODUCTION}

Peripheral arterial disease (PAD) is a systemic response to atherosclerosis. In Europe and North America, PAD affects approximately $16 \%$ of the population over 55 years of age. In patients over 70 years of age, various symptoms of PAD are seen in $20 \%$ of the population ${ }^{1}$. Intermittent claudication is a classic symptom of ischemic disease of the lower limbs. Slight to medium claudication affects $2-6 \%$ of males and $1-2 \%$ of females aged over 60 years $^{1}$. The femoropopliteal region is affected in $30 \%$ of patients with PAD. The superficial femoral artery (SFA) is atherosclerotically changed in the form of stenosis and/ or occlusions. Stenosis are typically short, less than $5 \mathrm{~cm}$ in length, as opposed to occlusions, which are often diffuse, severely calcified and longer than $5 \mathrm{~cm}\left(\right.$ ref. $\left.^{2}\right)$.

Diagnosis is based on physical examination, which includes measuring the ankle-brachial index, objectifying the claudication interval using the treadmill tester, examination by duplex sonography, and imaging methods (CT angiography, MR angiography, and digital subtraction angiography). The various imaging methods have their advantages and disadvantages and their indication often relies on the equipment and practice of the given institution. MR angiography is currently preferred, primarily due to the absence of risks associated with exposition to ionizing radiation, minimization of risks associated with administration of contrast agent, precise imaging and quantification of calcified stenosis, which CT angiography significantly overestimates.

Intermittent claudications are treated mainly conservatively. Conservative therapy includes an aggressive effort to decrease the risk factors for atherosclerosis, antiaggregation and vasoactive therapy and rehabilitation. A necessary requirement for a good result is cooperation of the patient during exercise aimed at prolonging the claudication interval. Maximum effect to prolong the claudication interval is achieved only when exercising under the supervision of a physiotherapist ${ }^{3}$.

If following conservative treatment the patient feels significantly restricted on walking, a form of revascularization is indicated. Revascularization in chronic occlusions of the femoropopliteal (FP) area is currently performed by two basic methods. A classical method is surgical revascularization using bypass technique with natural or artificial artery replacement - FP bypass. Another newer minimally-invasive method is endovascular treatment percutaneous transluminal angioplasty without stenting or with the implantation of stentgraft, and subintimal recanalization. Each of these revascularization methods and techniques has its advantages and disadvantages and thus limitations in their use. Knowledge and accessibility of all methods allows us to correctly indicate the proper type of procedure. Revascularization success, both surgical and endovascular, depends on the quality of the inflow and outflow tract. In patients with claudication, revasculariza- 
tion of the FP segment should not be indicated if there is a poor outflow tract, which requires placing the distal anastomosis of the bypass or terminating the endovascular recanalization on the III. segment of the popliteal artery (PA). Patients with claudication and poor outflow tract necessitating distal anastomosis of the bypass or termination of the endovascular recanalization to be placed on the III. segment of the popliteal artery should not be indicated for revascularization of the FP segment.

A case in point in the treatment PAD is patients with claudication with solely long occlusion of the SFA without affected AP or leg arteries. In simple terms a long occlusion of SFA is an occlusion longer than $10 \mathrm{~cm}$. These days with the expansion of the endovascular methods, is a relevant question to ask if surgical revascularization using bypass in still the best choise for treatment this specific group of patients.

The results of various types of treatment are evaluated according to technical success, primary patency, primary assisted patency and secondary patency ${ }^{4}$. The most used classification arising from recommendations of TransAtlantic Consensus is TASC (Inter-Society Consensus for the Management of Peripheal Arterial Disease), it was published in 2000 and revised in 2007 (ref. $^{1}$ ).

\section{METHODS OF REVASCULARIZATION AND THEIR RESULTS}

\section{Surgical treatment}

A classical surgical method of revascularization of a long occlusion of the SFA is femoropopliteal bypass extending from the CFA to the first segment of the PA. The affected segment is bypassed with a vascular graft, which may be an autologous vein- most often the great saphenous vein (GSV), an artificial vascular prosthesis or, in special cases, the umbilical vein or a cryopreserved vein is used $^{5}$. An artificial vascular prosthesis is indicated in cases where the vein has an unacceptable diameter (less than 3-4 $\mathrm{mm}$ ), varicose or postphlebitic changes. These changes are present in up to $30 \%$ of patients. The golden standard for vascular prostheses is a prosthesis from expanded polytetrafluorethylene - ePTFE. Utilization of prosthesis for revascularization is supported by a good outflow tract, a preserved plantar arc supplied by two lower leg arteries and/or patients with a short life expectancy ${ }^{5}$. Opinions regarding the recommended use of prosthesis in order to preserve the saphenous vein in patients with claudica- tions are arguable. On one hand they are supported by a shorter operation time, lower morbidity associated with a smaller operation wound and most importantly the GSV is preserved if needed for coronary bypass or a more distal reconstruction. A clear disadvantage of ePTFE prosthesis is the creation of a neointima, especially on the distal anastomosis. On the other hand quality reconstruction using autologous saphena vein has the lowest number of complications. Only a very small percentage of patients with intermittent claudication require the saphenous vein for coronary bypass ${ }^{6}$.

Femoropopliteal bypass with autologous vein has had the best revascularization results for decades and a metaanalysis of studies, performed by Pereira, confirms this fact $^{7}$. Primary patency when using the saphena vein after five years ranges between $75-84 \%$ (ref..$^{6-9}$ ). Eugster evaluated the results of only patients with intermittent claudication and presented an excellent primary patency after 10 years of $63.5 \%$ and primary assisted patency up to $87.3 \%$ (ref. $^{10}$ ).

Femoropopliteal bypass using ePTFE prosthesis is among the most commonly used alternatives to autologous vein. Early results of revascularization (up to two years after bypass) using prosthesis with distal anastomosis above the knee (proximal bypass) are comparable to results using autologous vein, after five years the results are significantly better in favor of the vein (49\% vs. $69 \%$ ) and results of studies after 10 years are lacking, with one exception $^{11}$. Another alternative to using autologous vein is a Dacron prosthesis. Results of studies comparing the results of Dacron and ePTFE prostheses for proximal bypass are contradictory. While Aune presents comparable results with primary patency of $58 \%$ after 5 years ${ }^{12}$, another multicentric study by Jensen showed a difference after 2 years favoring Dacron (76\% vs. 65\%) (ref. ${ }^{14}$ ). Results of individual studies based on the type of prosthesis used are shown in Tables 1-2.

A comparison between bypass using autologous vein and ePTFE prosthesis in patients with claudication under comparable conditions was performed by AbuRahma and Ballota. The main part of their method included performing the revascularization on one limb using autologous saphena vein and on the other limb using ePTFE prosthesis. After 5 and 6 years of follow-up the results of these revascularizations were comparable ${ }^{15,16}$.

Most authors showed that a predictive factor affecting the results of FP bypass is the quality of the outflow tract or the number of patent lower leg arteries and filling of

Table 1. Results of FP bypass - comparison between autologous vein (VSM) and ePTFE prosthesis.

\begin{tabular}{|c|c|c|c|c|c|c|c|c|c|c|c|c|}
\hline Author & \multicolumn{2}{|c|}{ AbuRahma } & \multicolumn{2}{|c|}{ Burger } & \multicolumn{2}{|c|}{ Klinkert } & \multicolumn{2}{|c|}{ Sala } & \multicolumn{2}{|c|}{ Ballotta } & \multicolumn{2}{|c|}{ Pereira } \\
\hline Year of publication & \multicolumn{2}{|c|}{1999} & \multicolumn{2}{|c|}{2000} & \multicolumn{2}{|c|}{2003} & \multicolumn{2}{|c|}{2003} & \multicolumn{2}{|c|}{2003} & \multicolumn{2}{|c|}{2006} \\
\hline Follow-up & \multicolumn{2}{|c|}{6 years } & \multicolumn{2}{|c|}{2 years } & \multicolumn{2}{|c|}{5 years } & \multicolumn{2}{|c|}{4 years } & \multicolumn{2}{|c|}{5 years } & \multicolumn{2}{|c|}{5 years } \\
\hline Number of patients & \multicolumn{2}{|c|}{43} & \multicolumn{2}{|c|}{136} & \multicolumn{2}{|c|}{151} & \multicolumn{2}{|c|}{75} & \multicolumn{2}{|c|}{51} & \multicolumn{2}{|c|}{-} \\
\hline Replacement used & VSM & ePTFE & VSM & ePTFE & VSM & ePTFE & VSM & ePTFE & VSM & ePTFE & VSM & ePTFE \\
\hline Primary patency in \% & 76 & 68 & 83 & 67 & 75.6 & 51.9 & 82.8 & 84 & 94 & 84 & 77.2 & 57.4 \\
\hline Secondary patency in \% & 85 & 77 & 83 & 77 & 79.7 & 57.2 & 80.6 & 79.5 & & & & \\
\hline Cummulative patency in $\%$ & 74 & 39 & & & & & 62 & 44 & & & & \\
\hline
\end{tabular}


Table 2. Results of FP bypass - comparison of results based on type of prosthesis used.

\begin{tabular}{lcccc}
\hline Author & Aune & \multicolumn{2}{c}{ Jensen } \\
\hline Year of publication & 2000 & \multicolumn{2}{c}{2007} \\
Follow-up & \multicolumn{2}{c}{5 years } & \multicolumn{2}{c}{2 years } \\
Number of patients & \multicolumn{2}{c}{103} & Dacron & ePTFE \\
Material & Dacron & ePTFE & 70 & 57 \\
Primary patency in \% & 58 & 58 & 76 & 65 \\
Secondary patency in \% & & & & 76 \\
\hline
\end{tabular}

Table 3. Results of endovascular methods.

\begin{tabular}{lccccc}
\hline Author & London & Saxon & Köcher & Scott & Kougias \\
\hline Year of publication & 1994 & 2007 & 2008 & 2008 & 2009 \\
Follow-up & 3 years & 4 years & 3 years & 3 years & 1 year \\
Method & SIR & Viabahn & SIR & SIR & SIR+Viabahn \\
Follow-up & 3 years & 4 years & 3 years & 3 years & 1 year \\
Number of patients & 200 & 76 & 123 & 472 & 57 \\
Primary patency in \% & & 55 & 48.4 & 25 & 75 \\
Primary assisted in \% & 56 & 67 & & 50 & 84 \\
Secondary patency in \% & & 79 & & & \\
\hline
\end{tabular}

the plantar arc. When evaluating the results of patients with intermittent claudication, most authors agree that it has not been established that they are influenced by the number of patent arteries ${ }^{14,16,17}$. Despite the good results of FP bypass mentioned above, the authors caution to carefully indicate these revascularizations in patients with intermittent claudication. They advise to maximize the utilization of conservative therapy possibilities. At the same time, Pereira in his meta-analysis discovered that in cases of bypass revascularization in patients with claudication, there is no reason to save the autologous saphena ${ }^{7}$.

\section{Endovascular methods for treating long occlusions of the SFA}

Endovascular treatment is based on percutaneous transluminal angioplasty (PTA). The goal of PTA is to dilate the pathologically changed arterial wall together with the atherosclerotic plaque. The main mechanism of angioplasty is the insertion of a lead wire into the narrowed or occluded arterial segment followed by dilation using balloon catheter of the entire media and part of the adventitia so that even the external diameter of the artery is extended. In cases of persisting stenosis after dilation, a stent/stentgraft may be applied. In the treatment of short stenosis or occlusions of the SFA, the best results are achieved with PTA. However, the technical success and results of this method in treating occlusions longer than $10 \mathrm{~cm}$ are not as convincing. One way of improving these results and maintaining long-term patency is stenting. Indications for primary stenting of the SFA and its results are often the subject of studies. Three randomized studies using PTA and nitinol stents were performed in patients with claudication ${ }^{18-20}$. Better results of primary stenting were achieved in patients with longer lesions. Primary stenting of lesions with an average occlusion length of $130 \mathrm{~mm}$ in a study by Schillinger was better than secondary stenting ${ }^{18}$.
PTA alone for long occlusions of the femoropopliteal segment has low primary technical success and poor long-term results with a high rate of restenosis. Another method improving the results of angioplasties in this area is subintimal recanalization (SIR). Its goal is to bypass the long occlusion of the artery through the subintimal space with subsequent dilation of this space. Dilation of the subintimal space and its patency may, in certain indicated cases, be supported by stent. The author of the SIR technique, A. Bolia reports a primary patency after SIR without stent of $71 \%$ after 12 months and $58 \%$ after 3 years ${ }^{21}$. Studies which include only patients with claudications after SIR present a clinical success rate of $58-90 \%$, a primary patency of $56 \%$ after one year, and primary assisted patency of $52-56 \%$ after 3 years ${ }^{22-25}$. Bolia reports that SIR is a treatment alternative in patients with claudication, who have a longer claudication interval and where the risks associated with bypass are too high ${ }^{21}$.

Dosluoglu reports that primary patency after SIR with selective stenting after one year increases to $50-85 \%$ $\left(\right.$ ref. $\left.^{2}\right)$. The frequency of selectively used stents in the femoropopliteal area is increasing. Nonetheless a retrospective study by Schmieder 12 months after SIR did not show a significant difference between patients with and without selective stent application ${ }^{26}$. In this study, however, the SIR group with stent had to undergo bypass more often than the SIR group without stent. This result may be due to the use of stent in cases of suboptimal results of SIR caused, for example, by calcifications or multiple lesions of the SFA. It has already been determined, that failure of SIR does not worsen the results of subsequent bypasses. The time period after SIR, which does not require further intervention ranges between 7,8 months to 3 years ${ }^{23,24}$.

Stentgraft implantation into a stenotic SFA is among the newer endovascular techniques. Advantages of a stentgraft include its ability to act against negative remodelation and minimize fractures and mechanical failure. A 
sufficient stentgraft diameter, the absence of massive calcifications in the artery, antiaggregation treatment and at least one patent lower leg artery are necessary to maintain patency ${ }^{27,28}$. Results of stentgraft implantation by Saxon after 4 years showed a $55 \%$ primary patency and $79 \%$ secondary patency; the results were not significantly affected by the length of the occlusion but by the diameter of the intervened artery ${ }^{28}$. In cases of long occlusions longer than $15 \mathrm{~cm}$ where SIR was combined with stentgraft, primary patency was $75 \%$ after one year as compared to $28 \%$ in patients with SIR alone ${ }^{29}$.

Results of individual endovascular methods are presented in Table 3.

\section{Results of studies comparing surgical and endovascular methods}

There are few studies which directly compare endovascular and surgical methods, especially longterm results are lacking. Comparison of studies is difficult due to differing study designs and study end-points, methods of follow-up and possibly the use of different types of stents.

Dosluoglu published a study, unfortunately which included patients with claudication as well as critical limb ischemia (CLI), which compared bypass with ePTFE prosthesis and PTA with stenting in patients with TASC $\mathrm{C}$ and $\mathrm{D}$ lesions. Despite the high percentage of patients with CLI in the bypass group, the primary patency of this group was $75 \%$ after two years. The PTA group with stents classified TASC C had significantly better patency (primary $80 \%$, secondary 98\%) than the PTA group TASC D ( primary $36 \%$, secondary $60 \%$.) The best results when compared to bypass was achieved by PTA group TASC C. Dosluoglu thus recommends that group TASC C receives initial treatment in the form of PTA with stent rather than revascularization using ePTFE prosthesis. Contrarily in patients with TASC D, PTA with stent should only be used in high-risk patients ${ }^{2}$.

Kedora published a study comparing patients who underwent FP bypasss using ePTFE prosthesis or endovascular treatment by stengraft (Viabahn). After 12 months, both groups had a comparable primary patency of $74 \%$, after two years $63 \%$. Not surprisingly, patency differed in patients classified TASC A/B, where patency was $64 \%$ after 2 years, and TASC C/D where patency was only $47 \%$. Even after 4 years both groups showed very comparable results ${ }^{30}$.

\section{CONCLUSION}

Ideal treatment of long occlusions of the femoropopliteal segment has not been established to date. In summation, it is apparent that the role of endovascular techniques used in the treatment of SFA occlusions is increasing. It is clear that PTA in combination with selective stent implantation is the method of choice in short SFA lesions. Primary stenting using self-expanding stents or stentgraft implantation into long SFA lesions shows good short-term results, which must, however, be con- firmed in long-term follow-up, especially in patients with intermittent claudication. Nonetheless, the premise still stands that lower risk patients with claudication should be examined to assess the quality of veins suitable for revascularization and bypass should be selected as the first method of choice.

\section{ACKNOWLEDGEMENT}

The work was supported by grant UP LF_2012_022.

Author contributions: JF, KV: literature search; JF: manuscript writing; $\mathrm{PU}, \mathrm{PB}, \mathrm{MK}$ : study design; $\mathrm{MC}, \mathrm{KV}$ : data collection; JF, PU, MK, MC: data interpretation; PB, PU, MK: manuscript revision.

Conflict of interest statement: The authors state that there are no conflicts of interest regarding the publication of this article.

\section{REFERENCES}

1. Norgreen L, Hiatt WR, Dormandy JA, Nehler MR, Harris KA, Fowkes FG. Inter-Society Consensus for the Management of Peripheal Arterial Disease (TASC II). J Vasc Surg 2007;45:5-67.

2. Dosluoglu HH, Lall P. Infrainguinal disease treatment: to stent or not to stent. J Cardiovasc Surg 2011;52:701-16.

3. Mika P, Wilk B, Mika A, Marchewka A, Nizankowski. The effect of pain-free treadmill training on fibrinogen, haematocrit, and lipid profile in patiens with claudication. Eur J Cardiovasc Prev Rehabil 2011;18:754-60.

4. Ruherford RB, Baker DJ, Ernst C, Johnston KW, Porter JM, Ahn S. Recommended standarts for reports dealing with lower extremity ischemia: revised version. J Vasc Surg 1997;26:517-38.

5. Gray BH. Endovascular Treatment of lower extremity Arterial Occlusive Disease: Femoropopliteal and tibial interventions. 151176 In Hallet JW jr,Mills JL, Earnshaw JJ, Reekers JA, Rooke TW. Comprehensive Vascular and Endovascular Surgery, 2nd edition, Elsiever 2009.

6. Klinkert P, Schepers A, Burger DHC, van Bockel JH, Breslau PJ. Vein versus polytetrafluorethylene in above-knee femoropopliteal bypass rafting: five-year results of randomized controlled trial. J Vasc Surg 2003;37:149-55.

7. Pereira CE, Albers M, Romiti M, Brochado-Neto CF, Pereira CA. Metaanalysis of femoropopliteal bypass grafts for lower extremity arterial insufficiency. J Vasc Surg 2006;44:510-17.

8. Veith FJ, Gupta SK, Ascer E, White-Flores S, Samson RH et all. Six-year prospective multicenter randomized comparison of autologous vein and expanded plytetrafluoroethylene grafts in infrainguinal arteries reconstruction. J Vasc Surg 1986;3:104-14.

9. Burger DH, Kappetein AP, Van Bockel JH, Breslau PJ. A prospective randomized trial comparing vein with polytetrafluoroethylene in aboveknee femoropopliteal bypass rafting. J Vasc Surg 2000;32:278-83.

10. Eugster T, Marti R, Gurke L, Stierli P. Ten year after arterial bypass Sumary for claudication: venous bypass in the primary procedure for TASC C and D lesions. World J Surg 2011;35:2328-31.

11. Kobayashi M, Hida K, Shikata H, Sakamoto S, Matsubara J. Long term outcome of femoropopliteal bypass for claudication and critical ischemia. Asian Cardiovasc Thorac Ann.2004;12:208-12.

12. Johansen $\mathrm{KH}$, Watson JC. Dacron femoro-popliteal bypass grafts in good-risk claudicant patiens. Am J Surg 2004;187:580-4.

13. Aune S, Laxdal E. Above-knee prosthetic femoropoliteal bypass for intermittent claudication. Results of the initial and secondary procedures. Eur J Vasc Endovasc Surg 2000;19:476-80.

14. Jensen LP, Lepäntalo M, Fossdal JE, RØder OC, Jensen BS, Madsen MS, Grenager O, Fasting H, Myhre HO, Baekgaard N, Nielsen OM, Helgstrand U, Schroeder TV. Dacron or PTFE for above-knee femoropopliteal bypass. A multicenter randomised study. Eur J Vasc Endovasc Surg 2007;34:44-9. 
15. AbuRahma AF, Robinson PA, Holt SM. Prospective controlled study of polytetrafluoroethylene versus saphenous vein in claudicant patients with bilateral above knee femoropopliteal bypasses. Surgery 1999; 126:594-601.

16. Ballotta E, Renon L, Toffano M, Da Giau G. Prospective randomized study on bilateral above- knee femoropopliteal revascularization: Polytetrafluoroethylene graft versus reversed saphenous vein. JVasc Surg 2003;38:1051-55.

17. Klinkert P, Post PN, Breslaw PJ, Bockej JH: Saphenous Vein Versus PTFE for Above-Knee Femoropopliteal Bypass. A review of the Literature. Eur J Vasc Endovasc Surg 2004;27:357-62.

18. Dick P, Wallner H, Sabeti S, Loewe C, Mlekusch W, Lammer J, Koppensteiner R, Minar E,Schillinger M. Balloon angioplasty versus stenting with nitinol stents in intermediate length superficial femoral artery lesions. Catheter Cardiovasc Interv 2009;74:1090-5.

19. Krankenberg $H$, Schlüter $M$, Steinkamp HJ, Bürgelin $K$, Scheinert $D$, Schulte KL, Minar E, Peeters P et all. Nitinol stent implantation versus percutaneous transluminal angioplasty in superficial femoral artery lesions up to $10 \mathrm{~cm}$ in length: the femoral artery stenting trial (FAST). Circulation 2007 17;116:285-92.

20. Laird JR, Katzen BT, Scheinert D, Lammer J, Carpenter J, Buchbinder M, Dave R, Ansel G, Lansky A, Cristea E, Collins TJ, Goldstein J, Jaff MR; RESILIENT Investigators. Nitinol stent implantation versus balloon angioplasty for lesions in the superficial femoral artery and proximal popliteal artery: twelve-month results from the RESILIENT randomized trial. Circ Cardiovasc Interv 2010:3:267-76.

21. Bolia A. Subintimal angioplasty in lower limb ischemia. J Cardiovasc Surg 2005;46:385-94

22. Met R, van Lieden KP, Koelemay MJW, Bipat S, Legemate DA, Reekers JA. Subintimal angioplasty for Peripheal Arterial Occlusive Disease: A Systematic Review. Cardiovasc Intervent Radiol 2008;3:687-97.
23. London NJM, Srinivasan R, Sayers RD, Hartshorne T, Ratliff DA, Bell PR. Subintimal angioplasty of femoropopliteal occlusions: the long term results. Eur J Vasc Surg 1994;8:148-55.

24. Scott EC, Biuckians A, Light RE, Burgess J, Meier GH, Panneton JM Subintimal angioplasty: Our experience in the treatment of 506 infrainguinal arterial occlusion J Vasc Surg 2008;48:878-84.

25. Köcher $M$, Černá $M$, Utíkal $P$, Kozák J, Šišola I, Bachleda $P$, Dráč $P$, Sekanina Z, Langová K. Subintimální angioplastika ve femoropopliteální oblasti - střednědobé výsledky. Ces Radiol 2008;62:153-5

26. Schmieder GC, Richardson Al, Scott EC, Stokes GK, Meier GH 3rd, Panneton JM. Selective stenting in subintimal angioplasty: analysis of primary stent outcomes. J Vasc Surg. 2008;48:1175-80.

27. Fischer M, Schwabe C, Schulte KL. Value of the Hemobahn/ Viabahn endoprosthesis in the treatment of long chronic lesions of the superficial femoral artery: 6 years of experience. J Endovasc Ther 2006;13:281-90.

28. Saxon RR, Coffman JM, Gooding JM, Ponec DJ. Long-term patency and clinical outcome of the Viabahn stent-graft for femoropopliteal artery obstructions. J Vasc Interv Radiol 2007;18:1341-9.

29. Kougias P, Chen A, Cagiannos C, Bechara CF, Huynh TT, Lin PH. Subintimal placement of covered stent versus subintimal balloon angioplasty in the treatment of long-segment superficial femoral artery occlusion. Am J Surg 2009;198:645-9.

30. Kedora J, Hohmann S, Garrett W, Munschaur C, Theune B, Gable D. Randomized comparison of percutaneous Viabahn stent grafts vs prosthetic femoral-popliteal bypass in the treatment of superficial femoral arterial occlusive disease. J Vasc Surg 2007;45:10-6.

31. Sala F, Hassem-Khodja R, Lecis A, Bouillanne PJ, Declemy S, Batt M Long-term outcome of femoral above-knee popliteal artery bypass using autologous saphenous vein versus expanded polytetrafluoroethylene grafts. Ann Vasc Surg 2003;17:401-7. 